\title{
Cotidiano da prática de atividade física de crianças e jovens com deficiências da Rede Municipal de Pelotas - RS
}

\author{
Laura Garcia Jung* \\ Alexandre Carriconde Marques** \\ Angélica Xavier Kalinoski*** \\ Gabriela Brisolara Xavier ${ }^{* * * *}$
}

\begin{abstract}
Resumo: O objetivo desta pesquisa foi mapear, de acordo com a visão dos pais e professores, o perfil dos alunos com deficiências pertencentes à Rede Pública Municipal de Ensino de Pelotas, descrevendo as práticas de atividades físicas nos ambientes internos e externos à escola. A amostra foi composta por 76 pais/responsáveis e 32 professores. Quanto ao tipo de deficiência, houve predomínio de déficit intelectual. De acordo com os professores, a maioria dos alunos participa das aulas de Educação Física. Os resultados demonstram que o processo inclusivo está sendo aprimorado no momento em que eles se inserem na sociedade e, consequentemente, estão cada vez mais obtendo oportunidades de se desenvolverem.
\end{abstract}

Palavras-chave: Estilo de Vida. Crianças com Deficiência. Educação Física escola. equidade

\section{INTRODUÇÃo}

A inserção de alunos com deficiências nas escolas regulares é recente na história do Brasil. Vive-se um período de transição, no qual a desqualificação dos professores, o preconceito e o despreparo

\footnotetext{
"Mestre em Educação Física. Escola Superior de Educação Física (ESEF). Universidade Federal de Pelotas (UFPEL). Pelotas. RS, Brasil. E-mail: lauragjung@gmail.com

"Professor. Escola Superior de Educação Física (ESEF). Universidade Federal de Pelotas (UFPEL). Pelotas. RS, Brasil. E-mail: amcarriconde@hotmail.com

"'Mestre em Educação Física. Escola Superior de Educação Física (ESEF). Universidade Federal de Pelotas (UFPEL). Pelotas. RS, Brasil. E-mail: angelica.kalinoski@gmail.com

"..."Mestrado em Educação Física. Escola Superior de Educação Física (ESEF). Universidade Federal de Pelotas (UFPEL). Pelotas. RS, Brasil. E-mail: gabrielabrisolara@gmail.com
} 
das famílias ainda têm sido barreiras para a prática inclusiva nas escolas (MARQUES, 2008). Por outro lado, com a evolução do conhecimento, o paradigma que percebia as pessoas com deficiências em razão das suas limitações e não pelas suas capacidades tem mudado significativamente.

Essa evolução tem sido sustentada pelo aumento dos estudos na área (CIDADE; FREITAS, 2005; SILVA, 2003; COSTA, 2009; MARQUES, 2008), em que se vislumbra uma participação efetiva das crianças e dos jovens com deficiências nas aulas de Educação Física (EF) em escolas regulares. A participação em ambientes não segregados pode favorecer uma mudança positiva do estilo de vida dessa população.

No entanto, pouco se sabe a respeito de como está acontecendo a inclusão nas escolas e qual é a participação dos alunos com deficiência nas atividades escolares. Em razão do exposto, o objetivo desse estudo foi mapear, na visão dos pais e professores, o perfil de crianças e jovens com deficiências, bem como explorar seu cotidiano relacionado com as práticas de atividades físicas nos ambientes internos e externos à escola, na Rede Pública Municipal de Ensino de Pelotas - RS.

\section{MÉtodos}

O presente trabalho consiste em um estudo epidemiológico descritivo (PEREIRA, 1995). A população foi constituída pelos pais e responsáveis dos alunos com deficiência que frequentam as escolas da Rede Pública Municipal de Ensino de Pelotas,RS, além dos professores de Educação Física desses alunos. A seleção da amostra foi intencional, onde 76 pais/responsáveis pelos alunos com deficiência e 32 professores se dispuseram a participar do estudo. Em razão da quantidade expressiva de crianças e jovens com déficit intelectual, optou-se que os pais ou responsáveis respondessem os questionários. A coleta de dados foi realizada no segundo semestre de 2010. 
Como instrumento de avaliação foi utilizado um questionário de estilo de vida adaptado (MARQUES; NAHAS, 2003) e um questionário sobre a relação entre a Educação Física e o processo inclusivo. $\mathrm{O}$ instrumento geral foi dividido em duas partes, respondido pelos pais e pelos professores de Educação Física. A parte destinada aos pais foi sobre dados de identificação, dados familiares, informações educacionais, informações sobre a deficiência, doenças associadas à deficiência, atividades da vida diária (AVDs), atividade física (AF) habitual, prática de esportes e percepção de saúde. A parte destinada aos professores correspondeu aos dados de identificação, formação profissional e participação do aluno com deficiência nas aulas de EF. Realizou-se uma parceria com o Centro de Apoio, Pesquisa e Tecnologias para Aprendizagem (CAPTA) para a obtenção da relação dos alunos. Os instrumentos foram entregues pelos pesquisadores ao coordenador pedagógico de cada escola, que passou o questionário para os pais e os professores responderem, retornando posteriormente para o pesquisador.

O projeto foi submetido ao Comitê de Ética em Pesquisa da Escola Superior de Educação Física (ESEF) da Universidade Federal de Pelotas (UFPel) e aprovado com protocolo n ${ }^{\circ}$ 151/2010.

Para a análise dos dados e descrição dos resultados, foram observadas as médias e frequências. As análises estatísticas foram feitas através do programa SPSS 13.0 for Windows.

\section{Resultados}

De acordo com o levantamento do CAPTA, das 90 escolas regulares existentes na rede municipal que possui 26.166 alunos e foram identificadas 70 escolas que atendem alunos com deficiência. Conforme informação dos educandários existem 236 estudantes ( $0,9 \%$ do total) com deficiência participando das atividades escolares. 


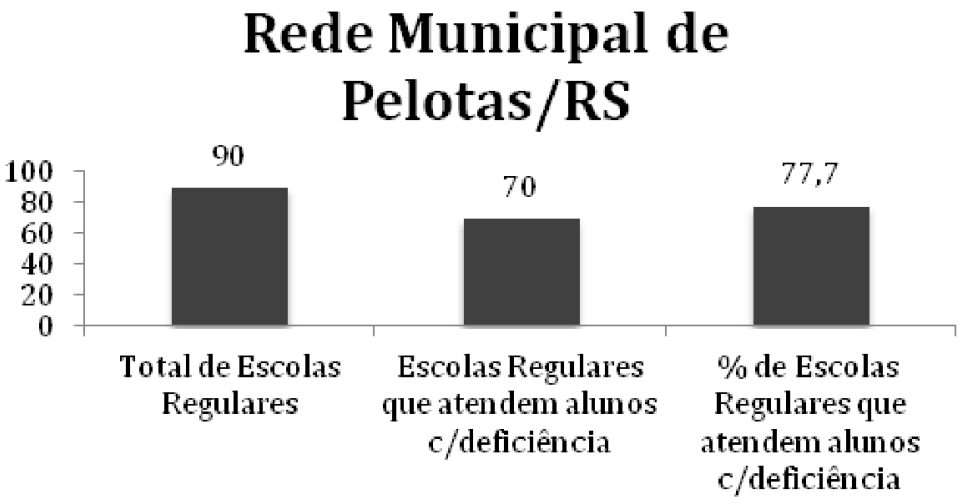

Gráfico 1: Distribuição das escolas regulares da rede municipal de Pelotas/RS em 2010

Fonte: Centro de Apoio, Pesquisa e Tecnologias para Aprendizagem

Com o retorno dos questionários, a amostra foi composta por $32,2 \%(n=76)$ responsáveis pelos alunos com deficiência matriculados na rede municipal de Pelotas, sendo, 73,7\% ( $\mathrm{n}=56)$ de mães; 11,8\% $(n=9)$ de pais; 2,6\% $(n=2)$ de irmãos; 2,6\% $(n=2)$ de padrastos; um professor e um outro parente; cinco pessoas não responderam à questão. Dos que responderam à questão, 80,3\% $(n=57)$ eram mulheres e 19,7\% (n=14) eram homens. Em 13,9 das famílias há mais de um filho com deficiência e o número médio de filhos por casal é de 2,7 $(\mathrm{DP}=1,2$ - min=1 e máx=7). Entende-se que a perda amostral não interferiu nos resultados, pois as características da população estudada (tipo de escola, deficiências, processo de inclusão, qualificação dos professores e outros) são similares. É interessante salientar que existe ainda nas escolas uma dificuldade para o retorno dos questionários, principalmente dos pais. Alguns motivos relacionados a isso são a falta de apoio das escolas à pesquisa, dificuldade de se encontrar os pais ou responsáveis, negação quanto à deficiência (há o diagnóstico, mas a família não aceita), dificuldade nos níveis de alfabetização dos respondentes e falta de interesse dos professores na interlocução do processo. 
Com relação ao sexo, observou-se que dos 74 que responderam à questão, 59,5\% (n=44) são do sexo masculino e 40,5\% $(\mathrm{n}=30)$ do sexo feminino, inseridos em 17 (24,3\%) diferentes escolas, com idades entre seis e 22 anos. Com relação ao nível socioeconômico (ABEP, 2010), observou-se que houve predomínio nas classes C e D. Quanto ao tipo de deficiência, houve prevalência da deficiência intelectual, conforme mostra a Tabela 1.

Tabela 1: Descrição da amostra quanto ao tipo de deficiência, sexo e nível socioeconômico.

\begin{tabular}{lcc}
\hline \multicolumn{1}{c}{ Descrição dos Alunos com Deficiências } & N (74)* & \% \\
\hline Deficiência & 59 & 79,7 \\
Intelectual & 08 & 10,8 \\
Física & 05 & 6,8 \\
Visual & 01 & 1,4 \\
Auditiva & 01 & 1,4 \\
Múltipla & & \\
Sexo & 44 & 59,5 \\
Masculino & 30 & 40,5 \\
Feminino & $\mathbf{N}$ & $\mathbf{7 6}$ \\
Nível Socioeconômico & 02 & 2,6 \\
A & 05 & 6,6 \\
B & 19 & 25,0 \\
C & 37 & 48,7 \\
D & 10 & 13,1 \\
E & 03 & 4,0 \\
Não responderam & & \\
\hline
\end{tabular}

Fonte: autores

*Houve perda em algumas questões e, por essa razão, foram indicados quantos no total responderam cada pergunta.

Ao verificar as informações educacionais, observa-se que os alunos com deficiência encontram-se inseridos do pré-escolar a $8^{\mathrm{a}}$ série, com predomínio nas séries iniciais até $4^{\mathrm{a}}$ série $(71 \%)$, sendo que $63,9 \%$ sabem ler e escrever; $70,3 \%$ frequentam a sala de recursos, $5,4 \%(n=4)$ também estão em escola especial no turno inverso e, $4,1 \%$ frequentam a sala de recursos e escola especial, conforme mostra a Tabela 2 . 
Tabela 2: Informações educacionais da amostra

\begin{tabular}{llc}
\hline \multicolumn{1}{c}{ Informações Educacionais } & N (76) & \% \\
\hline Sabe ler e escrever & 46 & 63,9 \\
Frequenta sala de recursos & 52 & 70,3 \\
Frequenta escola especial & 04 & 5,4 \\
Frequenta sala de recurso e escola especial & 03 & 4,1 \\
\hline
\end{tabular}

Fonte: autores

De acordo com as informações dadas pelos responsáveis, 29\% $(n=22)$ possuem alguma doença associada com a deficiência, sendo as doenças mais frequentes as pulmonares $27,3 \%(n=6)$ e as convulsões/epilepsia $22,7 \%(\mathrm{n}=5)$. Além disso, grande parte declarou perceber que a saúde dessas crianças e jovens é boa ou muito boa, conforme a Tabela 3 .

Tabela 3: Percepção dos pais sobre a saúde dos filhos

\begin{tabular}{lll}
\hline Saúde dos filhos & $\mathbf{N}(\mathbf{7 2})$ & \% \\
\hline Ruim & 0 & 0 \\
Regular & 12 & 16,7 \\
Boa & 31 & 43,1 \\
Muito boa & 18 & 25 \\
Excelente & 11 & 15,3 \\
\hline
\end{tabular}

Fonte: autores

Com relação às Atividades de Vida Diárias (AVDs) das pessoas com deficiência, a maioria consegue realizá-las sem dificuldade, conforme o gráfico. 


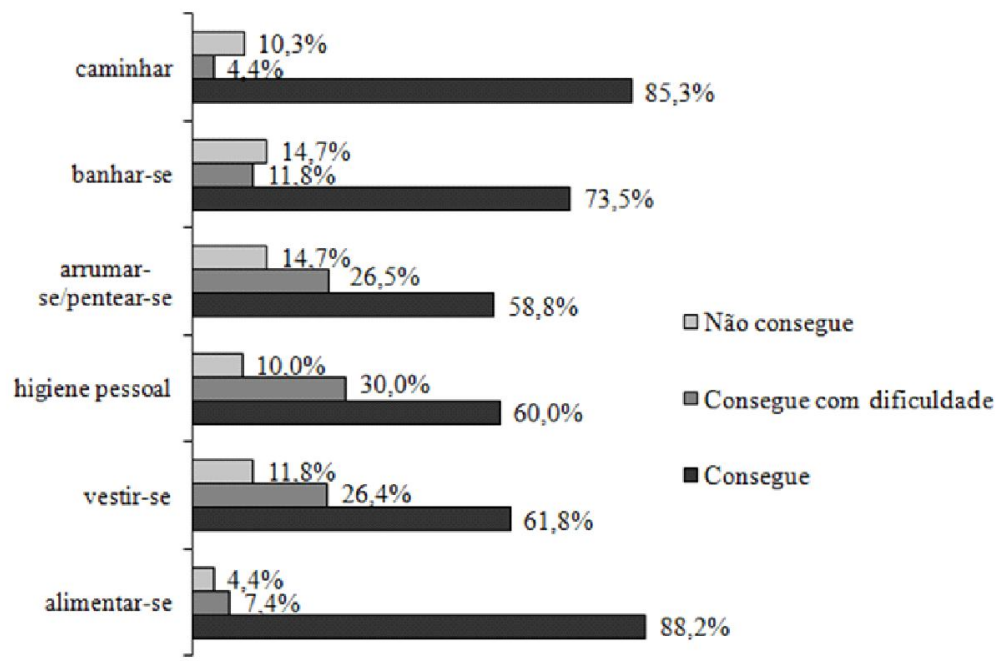

Gráfico 2: Nível de desenvolvimento das AVDs.

Fonte: autores

Ao serem questionados sobre a prática de AF - a qual incluía alguma atividade de lazer como jogos, brincadeiras, correr, caminhar e etc - $6,5 \%$ dos respondentes (pais ou responsáveis) afirmaram que seus filhos praticam alguma atividade. Já em relação ao deslocamento para a escola, 46,5\% $(\mathrm{n}=33)$ se deslocam a pé, $29,6 \%$ $(\mathrm{n}=21)$ de ônibus, $14,1 \%(\mathrm{n}=10)$ de carro ou moto, $5,6 \%(\mathrm{n}=4)$ de bicicleta, $4,2 \%(n=3)$ por outros meios de transporte e $7 \%(n=5)$ não responderam a questão. Em média, numa semana normal, eles caminham rapidamente ou andam de bicicleta em 4,4 dias ( $\mathrm{DP}=2,1)$, durante 1,2 horas $(\mathrm{DP}=0,93)$, para se deslocarem de um lugar para outro.

Com relação à prática esportiva nos ambientes externos à escola, apenas $32,8 \%(n=23)$ dos 70 respondentes afirmaram que seus filhos praticam algum esporte além das aulas de Educação Física, em média por 3,1 dias na semana com duração de 1,3 horas. Entre os que praticam o esporte preferido é o futebol $58,5 \%(\mathrm{n}=13)$, seguido da 
natação $36 \%$ (n=8), os demais 5,5\% ficam distribuídos entre atividade aeróbia, vôlei, tênis, skate e boxe, sendo que $18 \%(\mathrm{n}=4)$ praticam mais de uma modalidade ao mesmo tempo.

Assistir televisão $(34,7 \%)$ é a atividade mais realizada nos momentos de lazer. De segunda a sexta-feira, os alunos assistem em média 3 horas de televisão $(\mathrm{DP}=2,38)$; nos fins de semana esse número sobe para 4,1 horas $(\mathrm{DP}=2,38)$. Em relação ao tempo exposto ao computador e/ou vídeo game, durante a semana, a média ficou em 1,6 horas $(\mathrm{DP}=1,15)$; nos fins de semana, esse número sobe para 2,7 horas $(\mathrm{DP}=2,35)$.

A tabela 4 mostra as atividades físicas e as atividades realizadas nos momentos de lazer.

Tabela 4: Atividades físicas e atividades realizadas nos momentos de lazer

\begin{tabular}{lcc}
\hline \multicolumn{1}{c}{ Atividades Físicas e Lazer } & N (76) & \% \\
\hline Atividade física habitual & & \\
Pratica alguma atividade física & 39 & 56,5 \\
Desloca-se a pé para a escola & 33 & 46,5 \\
Pratica algum esporte além da EF & 23 & 33,8 \\
Atividade mais realizada no lazer & & \\
Assistir TV & 25 & 34,7 \\
Escutar música & 11 & 15,3 \\
Passear com a família ou amigos & 07 & 9,7 \\
Ler ou desenhar & 06 & 8,3 \\
Praticar atividade física & 06 & 8,3 \\
Conviver e conversar com amigos & 04 & 5,6 \\
Utilizar o computador & 04 & 5,6 \\
Brincar & 04 & 5,6 \\
Ajudar nas tarefas domésticas & 03 & 4,2 \\
Ficar sozinho & 02 & 2,8 \\
Não responderam & 04 & 5,6 \\
\hline
\end{tabular}

Fonte: autores

Com relação aos professores, a amostra foi composta por 12 homens $(37,5 \%)$ e 20 mulheres $(62,5 \%)$, com média de idade de 40,06 anos $(\mathrm{DP}=8,0-\min =24$ e $\max =58)$. Em relação ao tempo de formação, 21,9\% $(\mathrm{n}=07)$ dos professores concluíram sua graduação em média há cinco anos, 28,1\% $(\mathrm{n}=09)$ entre seis e 10 anos, 6,3\% $(n=02)$ entre 11 e 13 anos e 43,8\% $(n=14)$ há 14 anos ou mais. 
Dentre os professores, 59,4\% $(\mathrm{n}=19)$ possuem especialização em EF. Apenas oito (25\%) do total, possuem qualificação especializada para atender crianças com deficiência. Com relação a isso, observou-se uma associação significativa utilizando-se o teste do Qui-quadrado $(\mathrm{p}<0,01)$ em que os profissionais que não têm especialização na área são aqueles que percebem maior dificuldade para atuarem com essa população.

Ao serem questionados se concordam ou não com a inclusão na escola, nenhum deles afirmou discordar totalmente; $15,6 \%(\mathrm{n}=05)$ discordam em parte; 9,4\% ( $\mathrm{n}=03$ ) não concordam nem discordam; $56,3 \%(n=18)$ disseram que concordam em parte e $18,8 \%(n=06)$ concordam totalmente.

Sobre os conhecimentos para incluir os alunos com deficiência nas aulas, 21,9\% $(n=07)$ dos professores julgam ruins; 40,6\% $(n=13)$ regulares; $21,9 \%(\mathrm{n}=07)$ bons; $15,6 \%(\mathrm{n}=5)$ muito bons, porém nenhum dos professores julgou-os excelentes.

Quando interrogados se os conteúdos das aulas atendem às necessidades de todos os alunos, $12,9 \%(\mathrm{n}=04)$ disseram que sempre; para 48,4\% (n=15) quase sempre; ninguém afirmou que os conteúdos eram indiferentes; $38,7 \%(\mathrm{n}=12)$ às vezes e nenhum disse que nunca.

No que diz respeito à afirmação de que há uma promoção da inclusão por toda a comunidade escolar, 3,2\% $(\mathrm{n}=01)$ dos professores discorda totalmente dessa afirmação; 9,7\% (n=03) discordam em parte; $9,7 \%(n=03)$ não concordam nem discordam; 54,8\% $(n=17)$ concordam em parte e $22,6 \%(n=07)$ concordam totalmente.

De acordo com as respostas dos professores, 86,4\% $(n=51)$ dos alunos com deficiência participam das aulas, sendo que desses, $47,1 \%(n=24)$ participam ativamente de todas as atividades e 47,1\% $(\mathrm{n}=24)$ participam ativamente de algumas atividades e os $5,8 \%$ restantes dos alunos $(n=3)$ assistem sentados às aulas ou auxiliando o professor, conforme o gráfico: 


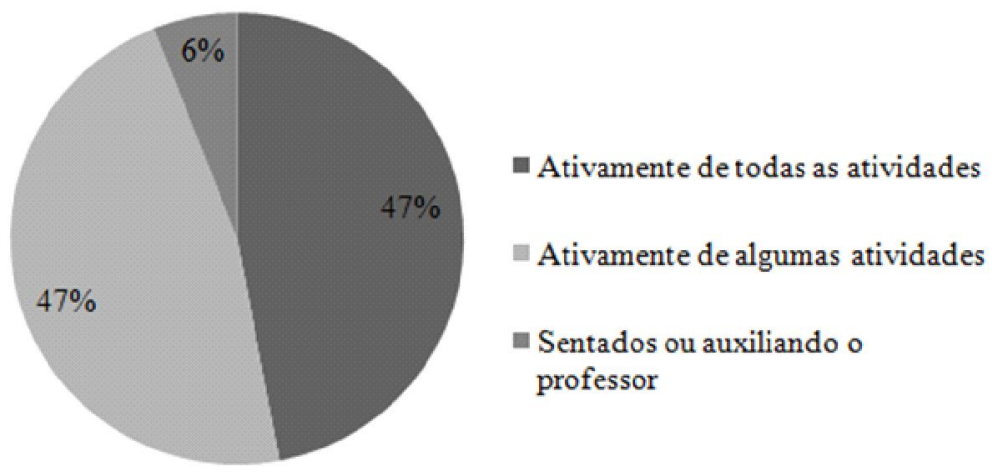

Gráfico 2: Forma de participação nas aulas por número de alunos com deficiência Fonte: autores

Entre os $14 \%$ que não participam das aulas, foram identificadas algumas razões, tais como: dispensa por atestado, dificuldade de relacionamento, falta de qualificação do professor para orientação e desinteresse pelas atividades.

Referindo-se ao interesse e a satisfação dos alunos com deficiência no desenvolvimento das atividades, dos 57 questionários que foram respondidos, 24,6\% $(\mathrm{n}=14)$ sempre são interessados; $29,8 \%(\mathrm{n}=17)$ quase sempre; 3,5\% ( $\mathrm{n}=2)$ se mostram indiferentes; $42,1 \%(n=24)$ se mostram interessados às vezes e nenhum dos professores afirmou que os alunos nunca demonstrem interesse pelas aulas, conforme a tabela 5:

Tabela 5: Nível de interesse e satisfação dos alunos com deficiência segundo os professores

\begin{tabular}{lll}
\hline Interesse e Satisf ação dos Alunos nas Atividades & $\mathbf{N}(\mathbf{5 7})$ & $\mathbf{\%}$ \\
\hline Sempre & 14 & 24,6 \\
Quase sempre & 17 & 29,8 \\
Indiferentes & 2 & 3,5 \\
Às vezes & 24 & 42,1 \\
Nunca & 0 & 0 \\
\hline
\end{tabular}

Fonte: autores

Movimento, Porto Alegre, v. 19, n. 02, p. 207-226, abr/jun de 2013. 
Quanto à aceitação dos alunos sem deficiência em relação aos alunos com deficiência, dos 57 respondentes $1,8 \%(n=1)$ rejeitam totalmente; $7 \%(n=4)$ rejeitam em parte; $7 \%(n=4)$ se mostram indiferentes à presença do aluno com deficiência; 50,9\% (n=29) aceitam em parte e 33,3\% (n=19) aceitam totalmente, de acordo com a percepção dos professores, conforme a tabela 6:

Tabela 6: Aceitação dos alunos sem deficiência em relação aos com deficiência segundo os professores

\begin{tabular}{lll}
\hline Aceitação dos Alunos sem Deficiência & $\mathbf{N}(\mathbf{5 7})$ & $\mathbf{\%}$ \\
\hline Aceitam totalmente & 19 & 33,3 \\
Aceitam em parte & 29 & 50,9 \\
Indiferentes & 04 & 7,0 \\
Rejeitam em parte & 04 & 7,0 \\
Rejeitam totalmente & 01 & 1,8 \\
\hline
\end{tabular}

Fonte: autores

\section{Discussão}

Entre os alunos com deficiência estudados, houve uma considerável prevalência de crianças e jovens com déficit intelectual. Entende-se, portanto, que a capacitação dos professores deve reforçar para esse tipo de situação e para estratégias de atuação com esses alunos.

Em relação ao número de crianças e adolescentes com deficiências matriculadas em escolas regulares no nível fundamental, um aumento anual progressivo, de acordo com dados do Instituto Nacional de Estudos e Pesquisas Educacionais Anísio Teixeira (INEP) em 2005 (KASPER; LOCH; PEREIRA, 2008).

Em relação à participação em atividades extraclasse, 70,3\% frequentam as salas de recursos multifuncionais, um ambiente oferecido pela Secretaria Municipal de Educação através do CAPTA, que responde pela Educação Especial e está ligado ao Departamento de Políticas Educacionais (DPE). Esse espaço oferece suporte às necessidades educativas especiais dos alunos e favorece seu acesso ao conhecimento, além de complementar o aprendizado obtido na escola regular. 
A Constituição Brasileira prevê que o atendimento educacional especializado deva ser oferecido fora da rede regular de ensino, em outros estabelecimentos, com o objetivo de ser um complemento e não um substitutivo da escolarização ministrada na rede regular para todos os alunos. Através deste complemento, a qualidade do processo de aprendizagem e assimilação dos conteúdos pelo aluno com deficiência será melhorada. Assim sendo, será possível favorecer uma inclusão de qualidade das pessoas com deficiência na escola e na sociedade.

A oportunidade de participarem de ambientes com crianças sem deficiências tem favorecido a melhoria das habilidades motoras e cognitivas de crianças e jovens com deficiências (MARQUES, 2008; LAW, et al, 2007). Ao serem verificadas as AVDs, a maioria consegue realizá-las sem dificuldade, o que mostra que as pessoas com deficiência estão adquirindo independência e autonomia e, provavelmente, isso se deva à mudança no estilo de vida estimulada pela inclusão nas escolas.

Em um sistema integrado, as oportunidades são comuns, favorecendo o desenvolvimento do ideal democrático através de um ambiente o menos restritivo possível (MANTOAN, 1995). Dessa forma, além das oportunidades recebidas, as pessoas sem deficiência estimularão as pessoas com deficiência a desenvolverem suas habilidades, especialmente no âmbito da Educação Física, pois essas atividades estarão relacionadas com a socialização entre ambos como também com as habilidades motoras, as quais são transferidas para as atividades da vida diária.

Em relação ao tempo de exposição à televisão, os alunos com deficiências não são diferentes das outras crianças sem deficiências, e para tanto, faz-se necessário uma atenção maior ao estímulo das práticas de AF em razão das próprias dificuldades naturais relacionadas ao tipo de deficiência. Assim como as crianças sem deficiência, aquelas que possuem alguma deficiência passam a utilizar o seu tempo livre em atividades com pouco dispêndio energético, principalmente as que se referem a equipamentos eletrônicos. Nesse estudo, observou-se que os níveis de AF não são tão baixos quanto 
os verificados em outros estudos (KOSMA; CARDINAL; MCCUBBIN, 2004; RIMMER, 2005a, 2005b), entretanto, torna-se necessário, no ambiente escolar, promover ações que estimulem a aderência dessas práticas.

Nos últimos anos, os cursos de graduação em EF vêm passando por um processo de transição, no qual disciplinas voltadas ao atendimento das pessoas com deficiências têm sido inseridas na grade curricular, possibilitando aos professores uma melhor formação para atuarem nessa área (LIMA et al, 2007). De acordo com Rodrigues (2008), a qualificação dos professores nas escolas regulares ainda é uma barreira na participação de crianças e jovens na prática de AF. No presente estudo, observou-se que $75 \%(n=24)$ não têm formação para trabalhar com crianças com deficiências. A associação encontrada entre a formação continuada (pós-graduação) e a dificuldade para trabalharem com alunos com deficiências preocupa, pois torna-se necessário melhorar a capacidade dos professores para atuarem com crianças e jovens com deficiência. Verificam-se, ainda, outras barreiras para a prática de AF, que são as limitações internas (a própria deficiência, doenças associadas, etc.) e as externas (superproteção, preconceito, ambientes inadequados, etc.) (MARQUES, 2008). Em um estudo realizado por Rimmer (2004), nos Estados Unidos, foram encontradas 178 barreiras e apenas 130 facilitadores para a prática de AF para pessoas com deficiência em estudo com grupos focais, ou seja, embora haja um número razoável de facilitadores para a prática, o número de barreiras ainda prevalece.

Observou-se que aproximadamente metade dos alunos estudados realiza deslocamento a pé, sendo que esse fato provavelmente ocorre em razão do nível socioeconômico (classe $\mathrm{C}$ e D) ou por residirem perto da escola. Existe nessa área, uma carência de estudos que relacionem AF para as pessoas com deficiência e que relatem um melhor atendimento a essa população (PITTETI; BEETS; COMBS, 2009).

A prática de esportes para crianças com deficiência é responsável também pelo desenvolvimento do comportamento humano, pois, através do conhecimento do seu corpo o indivíduo 
adquire a noção de si próprio, de suas limitações e de suas capacidades. Apenas um terço pratica algum esporte de forma recreativa além das aulas de EF. Além das questões da aptidão física, o esporte possui também um caráter social e esses fatores contribuem para a formação do indivíduo (CIDADE; FREITAS, 2005). A divulgação de competições para pessoas com deficiências (paralimpíadas e campeonatos nacionais) tem modificado a percepção da sociedade quanto à capacidade desses indivíduos em realizar tais atividades. Isso pode, de alguma forma, estimular a participação nas práticas esportivas, da mesma forma que as crianças sem deficiências se inspiram em seus ídolos.

De acordo com a percepção dos responsáveis pelas crianças e jovens, observou-se que a saúde deles é boa, tanto no aspecto emocional como físico, sendo assim um indicador favorável para a prática de $\mathrm{AF}$.

Em relação aos professores, percebe-se, em grande parte, dificuldade em trabalhar com crianças e jovens com deficiências, a qual está relacionada com a falta de programas de formação continuada que promovam o desenvolvimento profissional dos professores. Observou-se no presente estudo que a maioria dos professores não teve, na sua formação acadêmica, a possibilidade de trabalhar com disciplinas relacionadas às pessoas com deficiência.

A maioria dos professores $(75 \%)$ concorda com o processo inclusivo na escola, fortalecendo os resultados de um estudo com a mesma população realizado por Costa (2009), onde $57 \%$ dos professores afirmaram concordar com a inclusão. Esse resultado é positivo ao constatarmos que, em pouco tempo, a opinião das pessoas a favor da inclusão tem aumentado devido à ampliação das oportunidades de educação, lazer e emprego para as pessoas com deficiência. Isso pode estar ocorrendo pelo fato de que a cada ano um maior número de crianças e jovens com deficiência está ingressando nas escolas regulares, propiciando assim o contato entre deficientes e não deficientes e, consequentemente, a quebra de preconceito. Desde 2010, o número de salas de recursos passou de 
nove para 32 na rede municipal de ensino de Pelotas. O CAPTA estima que em 2012 foram atendidos cerca de 610 alunos com deficiência na rede.

Sobre os conhecimentos para incluir os alunos com deficiência nas aulas, outros estudos foram realizados anteriormente com a mesma população. Em um estudo de 2003, 64\% dos professores percebia fraca a qualificação para trabalhar com alunos com deficiência e apenas 3,6\% julgou boa; ao serem questionados sobre sua percepção para trabalhar com alunos com deficiência, 89,3\% não se sentiam preparados (SILVA, 2003). No estudo de 2009, 14\% acreditavam ter conhecimentos suficientes para o trabalho com alunos com deficiência, $21 \%$ consideravam-se preparados para o trabalho na disciplina de EF e 79\% diziam-se despreparados (COSTA, 2009). Dessa forma, há uma melhora considerável sobre os conhecimentos para incluir o aluno com deficiência no decorrer do processo inclusivo.

Quando interrogados se os conteúdos das aulas atendem às necessidades de todos os alunos, $61,3 \%$ entendem que os mesmos são adequados. No estudo de 2009, ao responderem a mesma pergunta, $43 \%$ dos professores afirmaram que os conteúdos atendem às necessidades de todos os alunos (COSTA, 2009). Percebe-se que há uma evolução do conhecimento dos professores, mesmo quando muitas vezes não se sentem preparados para atuarem com essa população. Isso ocorre à medida que os professores têm a oportunidade de vivenciarem o trabalho com este grupo de pessoas, entendendo que não há uma "receita especial" a ser desenvolvida.

Ao analisar duas turmas de $6^{\mathrm{a}}$ série em relação à aprendizagem de suas habilidades referentes aos fundamentos de basquete, antes e após o decorrer do bimestre, um estudo mostrou que não houve diferenças apesar de em uma das turmas haver três crianças com deficiência física (BLOCK, 1995). Esse estudo sugere que a presença de alunos com deficiência nas escolas regulares não atrapalha $o$ desenvolvimento dos demais, como também que os conteúdos podem atender às necessidades de todos sem prejudicar ninguém. Nesse estudo, a aceitação dos alunos sem deficiência em relação aos alunos com deficiência foi positiva, corroborando com um estudo que avaliou 
a aceitação dos colegas em relação ao aluno com deficiência, encontrando atitudes mais positivas no relacionamento entre os estudantes (TRIPP; FRENCH, SCHERRILL, 1995).

De acordo com os professores, 86,4\% dos alunos com deficiência participam das aulas, sendo que desses, praticamente todos participam ativamente de todas ou algumas atividades. Com esses dados é possível visualizar que a maioria deles tem condições de participar das aulas juntamente com os colegas. Meninos e meninas, deficientes e não deficientes, ocupando o mesmo espaço e praticando a mesma atividade esportiva podem, na convivência, aprender a relacionar-se e interagir com a diferença, em várias possibilidades, aprendendo a compartilhar e a resolver conflitos (CIDADE; BUSTO, 2008).

A ausência dos alunos que não participam das aulas (14\%) foi justificada por dispensa com atestado, dificuldade de relacionamento, falta de qualificação do professor para orientação ou desinteresse pelas atividades. Em alguns casos, será difícil a participação do aluno com deficiência nas aulas, porém os professores deverão tentar adaptar as atividades e tomar iniciativas que incentivem sua participação. Se não for possível, pelo menos estará presente no mesmo ambiente que os demais, onde de certa forma ele estará participando, o que será positivo. Observou-se que os alunos com deficiência têm um forte interesse em participarem das aulas de EF, sendo um aspecto positivo na educação para um estilo de vida ativo.

\section{Conclusões}

Os resultados desse estudo evidenciam que a maioria dos alunos que tem a oportunidade de estudar nas escolas regulares está participando das aulas de EF. Encontrou-se uma variedade de tipos de deficiências, demonstrando um avanço no atendimento dos alunos por parte dos professores. Mesmo que existam ainda algumas barreiras no processo de inclusão nas escolas regulares, observa-se que houve uma melhora no atendimento, comparado com estudos anteriores. Entende-se que a participação de um número maior de 
crianças nas atividades é reflexo do processo de inclusão, que tem levado conhecimento não só aos profissionais, mas também às famílias e à comunidade em geral, diminuindo as atitudes de preconceito. A participação efetiva das crianças e dos jovens com deficiências nas aulas de EF contribuirá para a sua formação em um ambiente alegre e saudável, propiciando o desenvolvimento de um estilo de vida ativo, refletindo, principalmente, na realização das suas atividades de vida diária com mais autonomia e independência. 


\begin{abstract}
Everyday physical activity of children and youth with disabilities from Pelotas-RS municipal schools

Abstract : This paper intended, from the point of view of parents and teachers, to establish the profile of disabled students from municipal schools in Pelotas, and to explore their daily habits with respect to physical activity in and out of school environment. The sample included 76 parents and 32 teachers. The most common disability was the intellectual deficit. According to teachers, most students participate in Physical Education Classes. The results demonstrate that the inclusive process is improved in the moment that disabled students are included in society and, consequently, achieve opportunities to develop themselves.

Keywords: Life style. Disabled children. Physical Education scholar. Equity
\end{abstract}

\section{Prácticas diarias de actividades físicas de niños y jóvenes con discapacidades en el municipio de Pelotas - RS \\ Resumen: La meta es mapear, de acuerdo con lo que piensan los padres y maestros, el perfil de los estudiantes con discapacidades pertenecientes a la Rede Pública Municipal de Ensino de Pelotas y explorar sus prácticas diarias relacionadas con las actividades físicas en la escuela en interiores y exteriores. La muestra estuvo conformada por 76 padres y 32 profesores. En cuanto a los tipos de discapacidad, hubo predominio el déficit intelectual. Según los profesores, la mayoría de los estudiantes participa en clases de educación física. Los resultados muestran que el proceso de inclusión se mejora cuando los estudiantes participan en la sociedad y, en consecuencia, tienen cada vez más y más oportunidades para desarrollarse.}

Palabras clave: Estilo de vida.Niños con Discapacidad. Educación Física escolar. Equidad 


\section{REFERÊNCIAS}

ASSOCIAÇÃO BRASILEIRA DE EMPRESAS DE PESQUISA (ABEP). Nível socioeconômico, 2010.

BLOCK, Martin E. Development and validation of the Children's Attitudes Toward Integrated Physical Education - Revised (CAIPE-R) Inventory. Adapted Physical Activity Quarterly, Champaign, IL. USA. v.12, p. 60-77, 1995.

CIDADE, Ruth E.; BUSTO, Rosângela M. Inclusão, Gênero e Deficiência. In: OLIVEIRA, A. A. B; PERIM, L. P. (Org.). Fundamentos pedagógicos para o Programa Segundo Tempo. Maringá: Editora da Universidade Estadual de Maringá, v.123138, 2008.

CIDADE, Ruth E.; FREITAS, Patrícia S. Introdução à Educação Física e ao Desporto para pessoas portadoras de deficiência. Curitiba: Ed. UFPR, 2005.

COSTA, Fábio R. B. Formação e desenvolvimento profissional em educação física dilemas e desafios na educação inclusiva. 2009. 95f. Dissertação (Mestrado) - Programa de Pós-Graduação em Educação Física. Universidade Federal de Pelotas, Pelotas.

KASPER, Andrea A.; LOCH, Márcia V. P.; PEREIRA, Vera Lúcia Duarte do Valle. Alunos com deficiência matriculados em escolas públicas de nível fundamental: Algumas considerações. Educar em Revista, Curitiba, Paraná, v. 31, p. 231-243, 2008.

KOSMA, Maria; CARDINAL, Bradley J.; MCCUBBIN, Jeffrey A. Predictors of physical activity stage of change among adults with physical disabilities. American Journal of Health Promotion. Troy, Michigan. 19: 114-7. 2004.

LAW, M.; PETRENCHK, T.; KING, G.; HURLEY, P. Perceived Environmental Barriers to Recreational, Community, and School Participation for Children and Youth With Physical Disabilities, Archives of Physical Medicine and Rehabilitation. Baltimore. v.88, n.12, p. 1636-1642, December,. 2007.

LIMA, Lana Ferreira; SANTOS, Cristiane da Silva; SOUZA e SILVA, Roseane Patrícia. O Profissional da Educação Física e a Inclusão dos Alunos com Deficiência no Ensino Regular. Poiésis Pedagógica. Goiás. v. 5/6 - p. 125-145 - Jan./Dez. 2007/2008.

MANTOAN, Maria Tereza E. Peculiaridades e semelhanças entre normais e deficientes face aos processos de desenvolvimento mental. Revista temas sobre desenvolvimento. São Paulo. Ano 5, no. 25. Julho. 1995, pp. 04 - 10.

MARQUES, Alexandre C. O perfil do estilo de vida de pessoas com Síndrome de Down e normas para avaliação da aptidão física. 2008. 162 f. Tese (Doutorado em Ciências do Movimento Humano) - Escola de Educação Física, Universidade Federal do Rio Grande do Sul, Porto Alegre. 
MARQUES, Alexandre C.; NAHAS, Markus Vinicius. Qualidade de vida de pessoas portadoras de Síndrome de Down, com mais de 40 anos no estado de Santa Catarina. Revista Brasileira de Ciência e Movimento. Brasília v. 11 n. 2, p. 5561, 2003.

PEREIRA, Maurício G. Epidemiologia: Teoria e Prática. Rio de Janeiro: Guanabara Koogan, 1995.

PITETTI, Kenneth H.; BEETS, Michael W.; COMBS, Cindy. Physical activity levels of children with intellectual disabilities during school. Medicine and Sciences and Sports Exercises. Indianapolis, IN. v.41, p.1580-1586, 2009.

RIMMER, James $\mathrm{H}$. Exercise and physical activity in persons aging with a physical disability. Physical Medicine Rehabilitation Clinics of North America. Philadelphia, USA. v.16 p. 41-56. 2005a.

RIMMER, James H. Review. Physical Medicine Rehabilitation Clinics of North America. Philadelphia, USA. v.16, n.1, p.41-56. Fev. 2005b.

RIMMER, James H.; Edward, et al. Physical activity participation among persons with disabilities: barriers and facilitators. American Journal of Preventive Medicine. Denville. 26: 419-25. 2004.

RODRIGUES, David A. A Educação Física perante a Educação Inclusiva: Reflexões Conceptuais e Metodológicas. Revista da Educação Física/UEM. Maringá, v.14, n.1, p. 67-73. 2003.

SILVA, Fernanda C. M. A percepção dos professores de Educação Física quanto à sua Qualificação para trabalharem com alunos Deficientes na Rede Municipal de Pelotas/RS. 2003. 44f. Monografia de Especialização. Curso de Especialização em Educação Física Escolar. Universidade Federal de Pelotas, Pelotas.

TRIPP, April; FRENCH, Ron; SCHERRILL, Claudine. Contact theory and attitudes of children in physical education programs toward peers with disabilities. Adapted Physical Activity Quarterly. Champaign, IL. USA. v.12, p.323-332, 1995.

Endereço para correspondência:

Laura Garcia Jung

Rua 35, n 379, Jardim Europa - Areal

Pelotas/RS

CEP: 96080-612

Recebido em: 26.06.2012

Aprovado em: 24.02.2013

ovimento, Porto Alegre, v. 19, n. 02, p. 207-226, abr/jun de 2013. 